\title{
Polymorph and Orientation Controls of Calcium Carbonate Crystals Achieved by Organic Matrices
}

\author{
Kimiyasu SATO, Yuri KUMAGAI, ${ }^{*}$ Toshihiro KOGURE, ${ }^{* *}$ Koji WATARI and Junzo TANAKA*** \\ National Institute of Advanced Industrial Science and Technology (AIST), \\ 2266-98, Anagahora, Shimoshidami, Moriyama-ku, Nagoya-shi, Aichi 463-8560 \\ *CREST, Japan Science and Technology Agency, 4-1-8, Honcho, Kawaguchi-shi, Saitama 332-0012 \\ ** Graduate School of Science, The University of Tokyo, 7-3-1, Hongo, Bunkyo-ku, Tokyo 113-0033 \\ ${ }^{* * *}$ Graduate School of Engineering, Tokyo Institute of Technology, 2-12-1, Ookayama, Meguro-ku, Tokyo 152-8550
}

\author{
有機マトリックスによる炭酸カルシウムの結晶相及び方位制御 \\ 佐藤公泰 $\cdot$ 熊谷友里 $*$. 小暮敏博** $\cdot$ 渡利広司 $\cdot$ 田中順三*** \\ 産業技術総合研究所, 463-8560 愛知県名古屋市守山区下志段味穴ヶ洞 2266-98 \\ *科学技術振興機構 CREST, 332-0012 埼玉県川口市本町 4-1-8 \\ **東京大学大学院理学系研究科, 113-0033 東京都文京区本郷 7-3-1 \\ ***東京工業大学大学院理工学研究科, 152-8550 東京都目黑区大岡山 2-12-1
}

\begin{abstract}
Crystallographic properties such as polymorphs and crystal orientations of calcium carbonate formed in biological systems can be controlled by interactions between organic matrices and inorganic substances. We have attempted to reveal such control mechanisms, using a polymerized Langmuir-Blodgett film of 10,12-pentacosadiynoic acid (PDA) as an organic matrix with highly regulated molecular alignment. Only calcite crystals were precipitated on the polymerized PDA film, even though in presence of $\mathbf{M g}^{2+}$ ions which were reported to enhance aragonite formation in previous works. The calcite precipitates were aligned on the PDA film with their $a$-axes in parallel to the polymerization direction. Calcite structure does not give a reasonable match over the molecular alignment of the PDA film along its $a$-axis. A concerted mechanism of geometric matching and stereochemical effect should determine the polymorphs and directions of calcium carbonate crystals on the organic matrices.

[Received May 21, 2006; Accepted August 24, 2006]
\end{abstract}

Key-words : Calcium carbonate, Biomineralization, Organic matrix, Polymorph, Crystal orientation

\section{Introduction}

Biomineralization processes, or biological syntheses of inorganic solids, often yield highly regulated structures under moderate conditions of temperature and pressure. In these processes, organisms create proper organic matrices, and the inorganic crystals successively precipitate onto the matrices by the chemical interactions at the inorganic/organic hetero-interfaces. The nucleation, growth and organization of biominerals are mediated by the supramolecular systems, and it is suggested that the interfacial interactions can control crystallographic properties of inorganic solids such as polymorphs and crystal orientations. Many current and evolving technologies require synthesis strategies that provide control over such crystallographic properties. Therefore, understanding of interactions at the inorganic/organic interfaces is a very important aspect of materials science. ${ }^{1)-4)}$

In biology several polymorphs of calcium carbonate are used, and the most abundant forms produced biologically are calcite and aragonite. One polymorph offers some advantages over the other, even though both have similar crystal structures. ${ }^{5)}$ Aragonite has the advantage of not having cleavage planes, but has the disadvantage of its small size and acicular morphology. Calcite tends to form large crystals but is very brittle. Organisms can circumvent the problems arising from calcite brittleness or aragonite tininess by the calcitearagonite dichotomy. Furthermore, in morphogenesis, crystallographic directions are also well defined. For instance, the elaborate shape of the calcium carbonate coccolith scales of a unicellular marine alga cannot be produced without precise directional control in crystals nucleation and growth. ${ }^{6}$
In the process of calcium carbonate formation in living bodies, the polymorph switching and growth directions are suggested to be controlled by organic polymers or membranes. As the controlling mechanism for the crystal growth mediated by organic matrices, two potential models, geometric model and stereochemical model, have been proposed..$^{7,8)}$ The geometric model is based on the idea that the close matching between lattice spacings in certain crystal faces and distances that separate functional groups periodically arranged on the organic surface determines the crystallographic features. The other model is focused on the stereochemistry at the interfaces between organic matrices and inorganic crystals. The outline of the model is as follows: when inorganic ions bind to the organic matrices, the resulting atomic arrangement around each organic functional group binding inorganic ions resembles the specific crystal structure to such an extent that the interfacial energy associated with nucleation of the crystal is specifically lowered. The controlling mechanism is, however, still obscure, because the interfaces between inorganic/organic materials in living bodies are so small and tangled that they cannot be studied directly. A model system that can reproduce the inorganic/organic interfaces is required for the study on the interactions. Langmuir monolayers, Langmuir-Blodgett (LB) films and self-assembled monolayers could offer adequate artificial molecular assemblages. ${ }^{9-11)}$ In our previous works, it was reported that the molecular assemblages with carboxyl groups induced nucleation and crystal growth of calcium phosphate in a body environment. ${ }^{12)-14)}$ In the present study, we fabricated an organic thin-film with carboxyl groups by the LB method and studied the growth process of calcium 
carbonate on the film.

We induced polymerization in the LB film as an organic matrix for calcium carbonate crystals formation. Berman et al. proposed availability of a polymerized LB film as an organic matrix due to its highly regulated molecular alignment. ${ }^{15)-17)}$ They reported that uniaxial alignment of calcium carbonate and cadmium sulfide crystals can be achieved when the crystals nucleated on the polymerized LB film. But they did not examine crystallographic direction of each single precipitate. We probed detailed crystallographic directions of the precipitates using the electron back-scatter diffraction (EBSD) method. ${ }^{18)}$ Surrounding environments also influence the polymorph, size and morphology of the resultant inorganic crystals. As to calcium carbonate crystals, many studies have shown that some additives own the ability to influence the crystallographic features. ${ }^{19)-22}$ In the present study, we attempted to reveal which effect is dominant in calcium carbonate crystals formation, geometric effect or stereochemical effect, using the organic template with regulated structure and an additive.

\section{Experimental Methods}

Polymerized LB film of 10,12-pentacosadiynoic acid (PDA: $\left.\mathrm{CH}_{3}\left(\mathrm{CH}_{2}\right)_{11} \mathrm{C} \equiv \mathrm{CC} \equiv \mathrm{C}\left(\mathrm{CH}_{2}\right)_{8} \mathrm{COOH}\right)$, a 25-C long chain with a diacetylene functionality, was prepared according to a method reported in a previous work. ${ }^{23)}$ Monomeric PDA was dissolved in chloroform with concentration of $1 \mathrm{mM}$, and $300 \mu \mathrm{l}$ of the solution obtained was spread on a subphase of ion-exchanged distilled water. After chloroform was evaporated for $5 \mathrm{~min}$., the residual organic film was slowly compressed up to a surface pressure needed for the ordering of the organic molecules, typically $20 \mathrm{mN} \cdot \mathrm{m}^{-1}$, and allowed to equilibrate for $30 \mathrm{~min}$. The organic thin-film was polymerized in-situ with $254 \mathrm{~nm}$ UV light. The ordered and packed structure of the organic molecules on the water surface results in a linear conjugated polymer. Fused-silica glass slides (hydrophobized with 1,1,1,3,3,3-hexamethyldisilazane beforehand) of $13 \times 38$ $\times 1 \mathrm{~mm}^{3}$ in size were used as substrates. The polymerized PDA film was transferred to the fused silica substrates or carbon micro grids supported by copper meshes using a horizontally lifting method.

Crystals were grown from a supersaturated solution with respect to calcium carbonate. The supersaturated solution was prepared using the method by $\mathrm{Kitano}^{24)}$ with some modifications. $\mathrm{CaCO}_{3}$ was suspended in distilled water and carbon dioxide gas was bubbled into a stirred suspension for $3 \mathrm{~h}$ at room temperature. The remaining $\mathrm{CaCO}_{3}$ solids were removed by filtration. A further period of bubbling $(0.5 \mathrm{~h})$ was then employed to dissolve any crystal nuclei. A solution containing $\mathrm{Mg}^{2+}$ ion $\left(\left[\mathrm{Mg}^{2+}\right] /\left[\mathrm{Ca}^{2+}\right]=10.0\right)$ was obtained by adding $\mathrm{MgCl}_{2}$ to the solution. The polymerized LB films supported by the fused-silica substrates were soaked in the supersaturated solutions to deposit calcium carbonate crystals onto the film surface.

After gently washed with ion-exchanged distilled water and dried at room temperature, the specimens were evaluated by scanning electron microscopy (SEM) and transmission electron microscopy (TEM). The surface topography of the crystals was investigated using an SEM (S-4500, HITACHI) operated at 5-20 kV. Polymorphs and crystallographic directions of the precipitates were analyzed using an EBSD system (PhaseID, Thermo NORAN, USA) equipped to the SEM. Samples for TEM were sonicated in an appropriate amount of ethanol and the precipitates and the polymerized films were suspended in the ethanol. A droplet of the suspension was
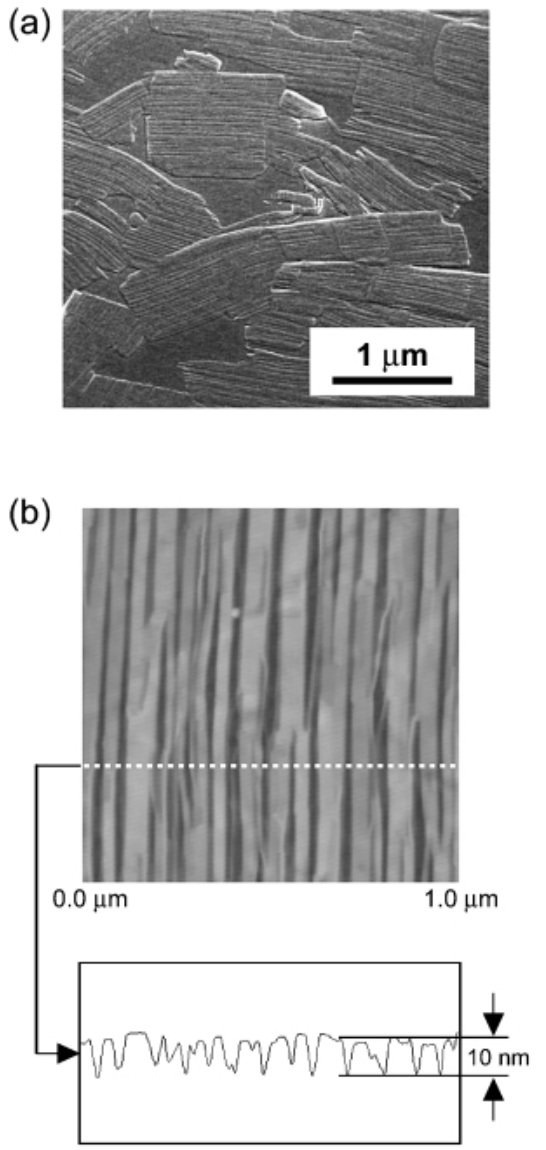

Fig. 1. (a) SEM image of the polymerized PDA film transferred onto a fused silica substrate. (b) AFM image of the polymerized PDA film and cross-sectional analysis.

transferred onto carbon micro grid supported by a cupper mesh, and ethanol was removed by a filter paper. TEM observations were performed using a JEM-2010 microscope (JEOL) equipped with an energy dispersive X-ray spectrometer (EDS), operated at $200 \mathrm{kV}$. The morphology of the organic thin-film was investigated by an atomic force microscope (AFM) (NanoScope III-a, Digital Instruments, USA). Tapping mode with a silicon single crystal cantilever (spring constant: $40 \mathrm{~N} / \mathrm{m}$ ) was employed for the observation.

\section{Results and discussion}

\subsection{Characterization of the polymerized PDA film}

Figure 1(a) shows an SEM image of the polymerized PDA film transferred onto a fused silica substrate. Although the PDA film is very thin, we have successfully observed the film with the high-resolution SEM. The image indicates that the film consists of domains in which many parallel slits are formed on the substrate. AFM imaging of the polymerized PDA film also shows the parallel slits identical with those in the SEM image (Fig. 1(b)). The film was cracked in the process of the directional polymerization of PDA, and the slits are parallel to the polymerization direction. ${ }^{25)}$ The polymerized PDA film is about $10 \mathrm{~nm}$ thick from the sectional analysis of the AFM image. Assuming trans-trans conformation for the two alkyl chains in a PDA molecule, monolayer thickness is calculated to be about $3.3 \mathrm{~nm} .{ }^{26)}$ The film is most likely a trilayer, and the hydrocarbon side chains lie almost perpendicular to the film plane. Figure 2 (a) shows a TEM image of 
(a)

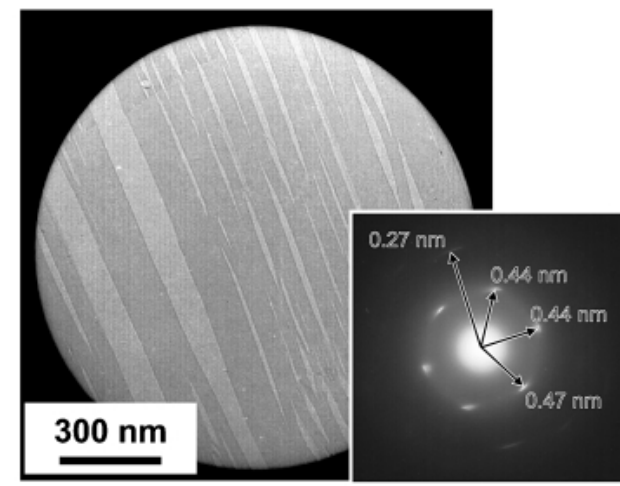

(b)

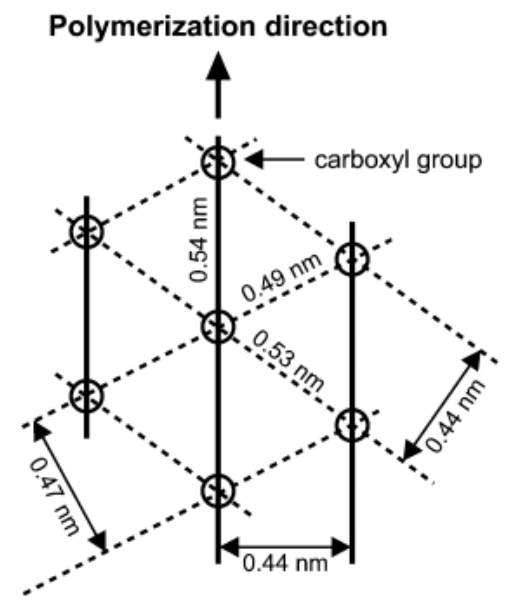

Fig. 2. (a) TEM image and SAED pattern of the polymerized PDA film. (b) Polymerized PDA film structure schematic. The open circles represent the positions of PDA molecules that correspond to the positions of carboxyl groups. the polymerized PDA film transferred on a carbon micro grid instead of fused silica and the corresponding selected-area electron diffraction (SAED) pattern. The SAED pattern shows eight diffraction spots in the reciprocal plane. The molecular arrangement in the polymerized film expected from the SAED pattern is shown in Fig. 2(b). The PDA molecules (or carboxyl groups) are in slightly distorted hexagonal arrangement. The periodicity along the polymerization direction is $0.54 \mathrm{~nm}$ and the distance between neighboring polymers is $0.44 \mathrm{~nm}$. The obtained values are reasonable when compared with the values reported in the preceding works. ${ }^{15), 27), 28)}$

\subsection{Crystals grown from the $\mathrm{Mg}^{2+}$ free solution}

Figure 3 shows SEM micrographs of the surface with the PDA film soaked in the supersaturated solution for $3 \mathrm{~h}$. The surface of the substrate was covered with euhedral precipitates (Fig. 3(a)). EBSD measurement indicates that the precipitated materials are calcite single crystals. SEM micrographs with higher magnification (Figs. 3(b)-3(e)) revealed that the calcite crystals over a single PDA film domain are uniformly coaligned. One crystal edge was precisely aligned parallel to the polymerization direction as shown in Fig. 3d. On the other hand, needle-like crystals grown on foreign dust particles were found occasionally (Fig. 3(f)). These crystals were identified as aragonite using EBSD technique. However, directly upon the PDA films, few calcium carbonate phases other than calcite were found.

The strategy we have adopted here is to examine the geometric relationship between polymerized PDA films and calcite crystals accurately using EBSD, and to evaluate the most important factor for the crystal orientation control. The crystal structure of calcite is ascribed to rhombohedral symmetry with the space group $R \overline{3} c$, but is expressed according to hexagonal symmetry for clarity. We examined eight precipitates upon the PDA films by EBSD technique, and evaluated the orientation variation in the $a$-axis $(\langle 100\rangle$ direction) and $c$-axis $([001]$ direction $)$. Inclinations of the two axes against the basal plane are shown in Fig. $4(a)$, and the values of inclinations are plotted in a scattergram (Fig. 4 (b) ). Standard deviations for the $a$ - and $c$-axes are 1.30 and

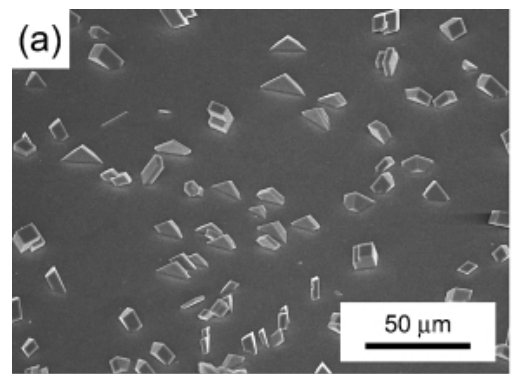

(d)

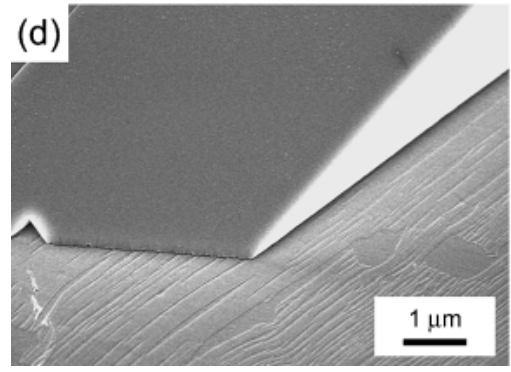

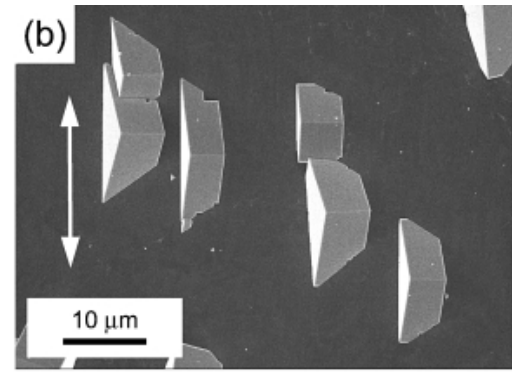

(e)

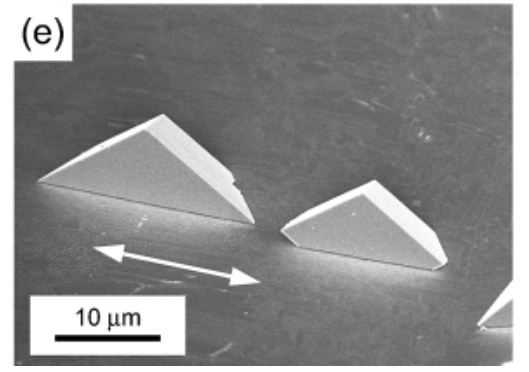

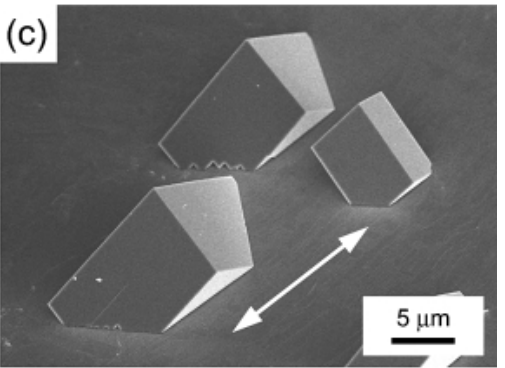

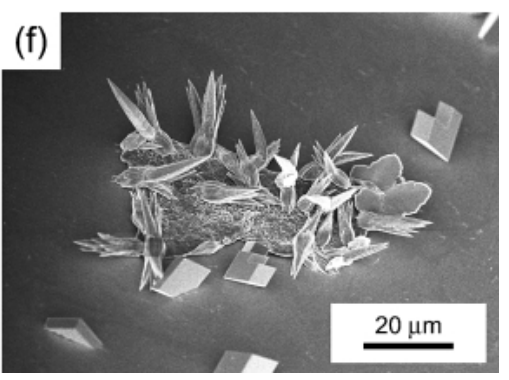

Fig. 3. SEM images of the calcium carbonate precipitates formed on the polymerized PDA film from the $\mathrm{Mg}^{2+}$ free solution. White arrows indicate the directions of polymerization. (a) The substrate surface covered with calcite crystals. (b)-(e) Calcite single crystals aligned on the PDA film. (f) Needle-like aragonite crystals grown on foreign dust particles. 
(a)
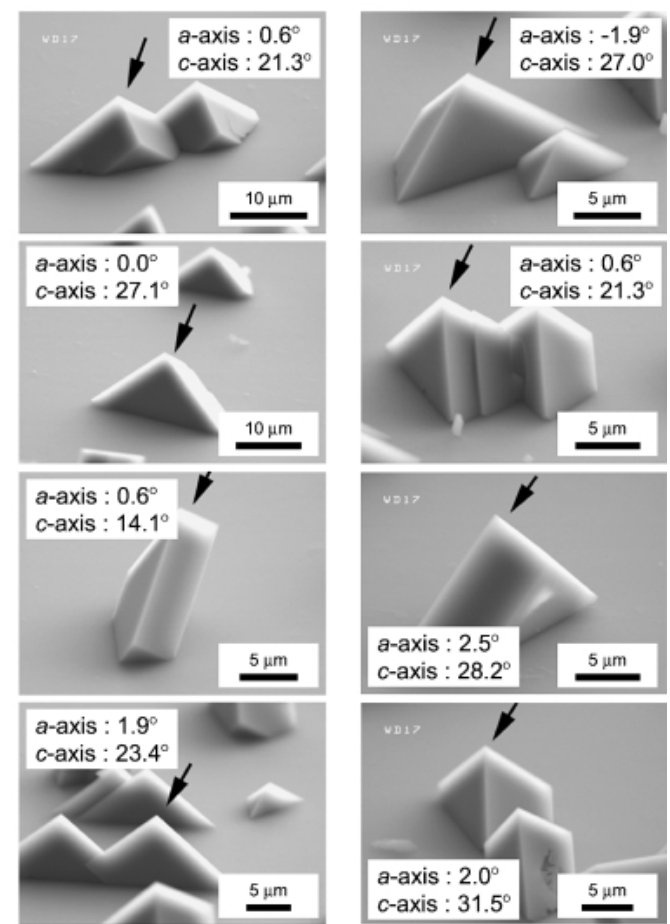

(b)

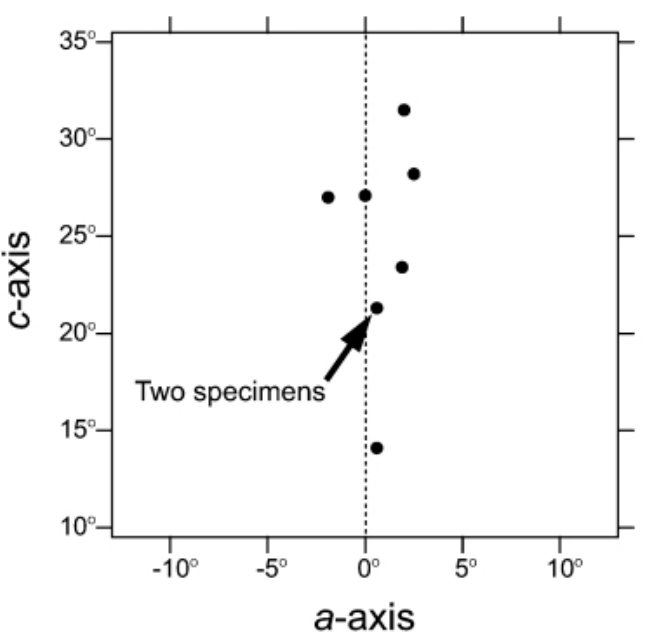

Fig. 4. Results of the EBSD analysis on the calcite precipitates. (a) SEM images of analyzed precipitates, which are indicated by arrows. (b) Scattergram showing the inclinations of the $a$ - and $c$-axes against the substrate plane.

5.06, respectively. Undoubtedly the $c$-axis inclination varies more widely than that of the $a$-axis. The crystal edge aligned parallel to the polymerization direction, which is shown in Fig. $3 \mathrm{~d}$, corresponds to the direction of the $a$-axis. It is concluded that the $a$-axes of the calcite precipitates are controlled to be in parallel to the polymerization direction, but the $c$-axes inclinations disperse around $25^{\circ}$.

3.3 Crystals grown from the $\mathrm{Mg}^{2+}$ containing solution

Many previous works reported that the calcium carbonate polymorph most commonly obtained from solutions in the presence of $\mathrm{Mg}^{2+}$ ion is aragonite. In absence of seeding calcite crystals, it is possible to obtain calcite phases in solution only for $\left[\mathrm{Mg}^{2+}\right] /\left[\mathrm{Ca}^{2+}\right]$ molar ratio up to 3-4. At higher ratios only aragonite precipitation is observed. ${ }^{29)}$ This is because $\mathrm{Mg}^{2+}$ ions selectively adsorb on the crystal surface of
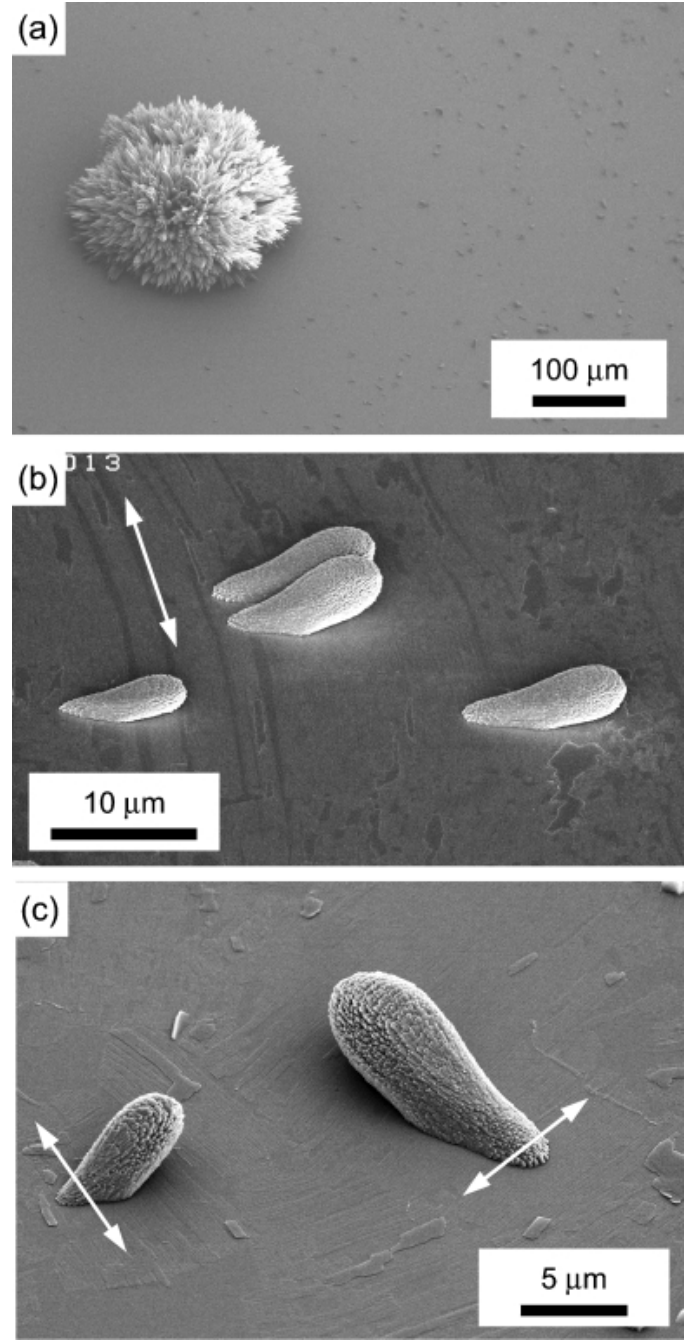

Fig. 5. SEM images of the calcium carbonate crystals grown on the polymerized PDA film from the $\mathrm{Mg}^{2+}$ containing solution. White arrows indicate the directions of polymerization. (a) An aggregate of needle-like aragonite crystals. (b) and (c) Water-drop shaped calcite single crystals aligned on the PDA film.

the calcite and suppresses the growth of calcite remarkably. ${ }^{30)}$ It is also expected that the solubility of calcite increases due to accumulated lattice strain caused by incorporated $\mathrm{Mg}^{2+}$ ions. $^{31)}$

Figure 5 (a) shows a low-magnified SEM image of the polymerized PDA film surface soaked in the $\mathrm{Mg}^{2+}$ containing supersaturated solution for $3 \mathrm{~d}$. Very large aggregates of needle-like crystals were occasionally observed. These crystals were identified as aragonite by EBSD. Although the volume of the aggregates is not small, they were probably induced by some foreign particles as shown in Fig. 3(f), not by the polymerized PDA film, because the density of the aggregates is extremely low. On the other hand, precipitates of about $10 \mu \mathrm{m}$ in size with water-drop shape are observed on the surface of the film (Figs. 5(b) and 5(c)). In the figures many parallel slits corresponding to the polymerization direction are also imaged on the film. The water-drop shaped precipitates are uniformly oriented; their longitudinal axes are at a right angle with the slits.

Figure 6 (a) shows a TEM bright field image of a precipitate and corresponding SAED pattern. The SAED patterns from 

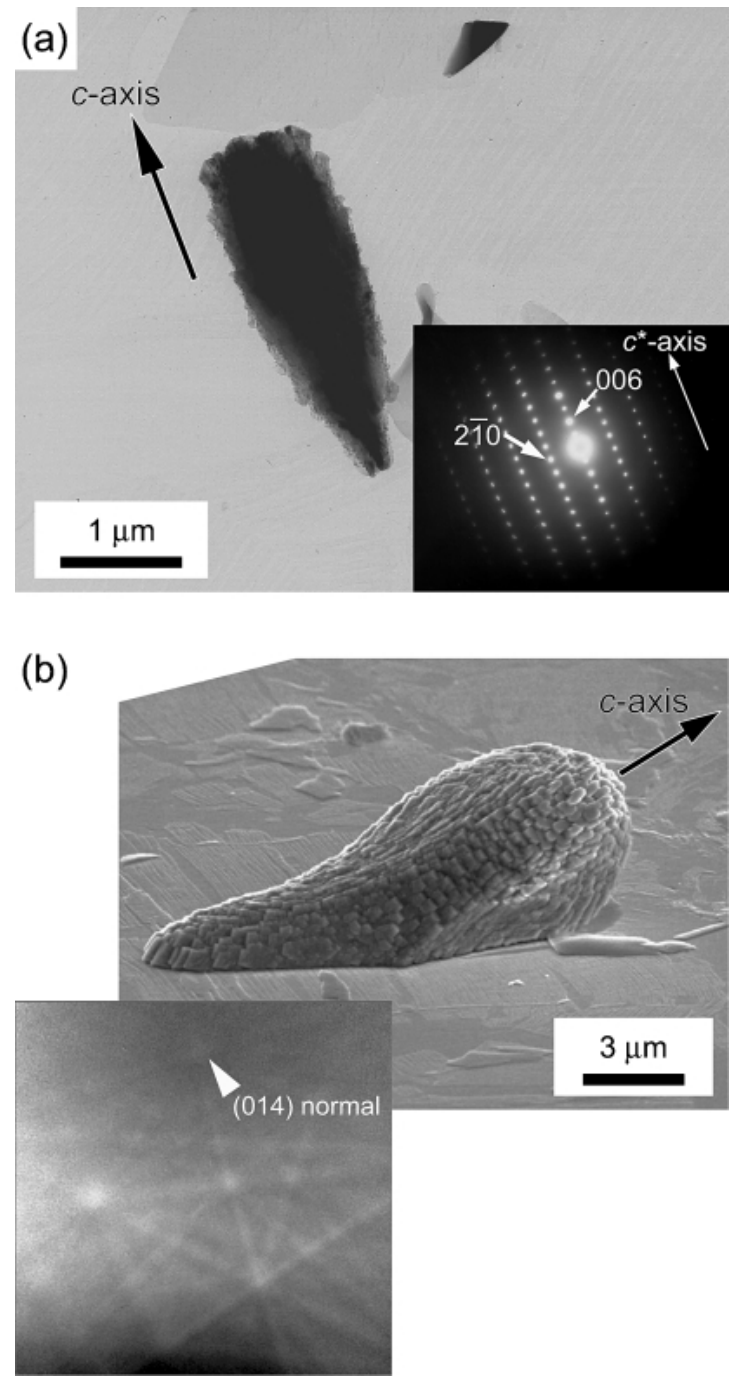

Fig. 6. (a) TEM image and SAED pattern of a calcite precipitate. The calcite single crystal was viewed from the [120] direction. (b) Result of the EBSD analysis on a calcite precipitate. SEM image of an analyzed precipitate and the corresponding EBSD pattern are shown. The EBSD pattern indicates that the calcite precipitate grew with its (014) facet parallel to the substrate.

the precipitates indicate that they are calcite single crystals, despite their rough surface. The calcite $c$-axis is along the longitudinal direction of the water-drop shape. Therefore, the calcite single crystals are aligned with their $c$-axes perpendicular to the polymerization direction of the PDA film. EDS analyses of the specimens showed a considerable amount of $\mathrm{Mg}^{2+}$ ions (approximately $30 \mathrm{~mol} \%$ ) in the crystal, indicating that the obtained precipitates are magnesian calcite. It is known that magnesian calcite can contain $\mathrm{Mg}^{2+}$ ions up to over 30 mol\% in solid solution. ${ }^{32)}$ Synthetic calcite usually grows as an almost isotropic rhombohedron delimited by a set of equivalent oblique $\{104\}$ facets in the hexagonal lattice for which the calcium and carbonate ions are closely packed along these facets to obtain the most thermodynamics stability. ${ }^{5)}$ But $\mathrm{Mg}^{2+}$ ions caused the remarkable change in the morphology of calcite. Figure 6(b) illustrates the result of the combined use of SEM and EBSD techniques on the precipitate. The calcite single crystal adheres to the PDA film with (014) facet, i.e., its $c$-axis was inclined by $45^{\circ}$ against the basal plane. EBSD analyses for several single crystals revealed a tendency similar to that of the $\mathrm{Mg}^{2+}$-free experiments despite the prominent difference in morphologies. The directions of the $a$-axes of the calcite precipitates and the polymerization direction of the PDA film were in fairly precise agreement. Inclinations of the $c$-axes from the substrate had some dispersion.

\subsection{Polymorphs selection and orientation control}

Calcite is the only thermodynamically stable phase of calcium carbonate at the ambient temperature. However, as denoted above, previous works reported that the calcium carbonate polymorph expected from the $\mathrm{Mg}^{2+}$-rich solution is aragonite. $\mathrm{Mg}^{2+}$ ions act as an inhibitor for the calcite crystal growth and affect the selection of the polymorphs. In the present study, foreign particles on the film probably played the role of nuclei and induced needle-like aragonite crystals. Only the calcite structure was found upon the polymerized PDA film. This result indicates that the initial stage of crystal nucleation determines the polymorph of following crystals growth, and the PDA film may exert a control over the polymorphism through the initial nuclei formation.

Although the crystal structure of aragonite is orthorhombic symmetry, calcite and aragonite have very similar crystal structures. Both calcite and aragonite crystal structures are composed of alternating layers of $\mathrm{Ca}^{2+}$ ions and $\mathrm{CO}_{3}{ }^{2-}$ ions perpendicular to their $c$-axes. The $\mathrm{Ca}^{2+}$ ions occupy almost the same lattice positions in the (001) plane, and in the both structures the $\mathrm{CO}_{3}{ }^{2-}$ ions lie with their molecular planes parallel to the $(001)$ plane. In the aragonite structure, some of the $\mathrm{CO}_{3}{ }^{2-}$ ions are shifted along the $c$-axis direction to form two layers, and the $\mathrm{CO}_{3}{ }^{2-}$ ions orientations in the two layers are different. The shift results in the different properties of these two polymorphs. The $\mathrm{Ca}^{2+}$ ions are arranged in the calcite (001) plane in a hexagonal lattice with a uniform spacing of $0.499 \mathrm{~nm}$, while in the aragonite (001) plane there is a pseudo-hexagonal arrangement of $\mathrm{Ca}^{2+}$ ions spacing at a distances of either 0.496 or $0.797 \mathrm{~nm}$ along the orthogonal $a$ - and $b$-axes, respectively (Fig. 7). Neither calcite structure nor aragonite structure gives a reasonable match over the molecular alignment of the PDA film, which has the carboxyl groups spacing of 0.54 $\mathrm{nm}$ along the polymerization direction (Fig. 2). However, only calcite crystals precipitated on the PDA film, irrespective of whether the supersaturated solutions contained $\mathrm{Mg}^{2+}$ ions or not. In the PDA film, there is a pseudo-hexagonal molecular alignment. Among the three almost equivalent directions in the pseudo-hexagonal structure, the $a$-axes of calcite were aligned only along the polymerization direction. The phase switching and the directional regulation cannot be explained when only the geometric match is taken into account. Therefore, not only geometric factors but also other factors, for instance, stereochemical factors, should be important.

In both of the above experiments, obtained calcite crystals were aligned on the polymerized PDA film. Their $a$-axes were along the polymerization direction almost perfectly, whereas the inclination of $c$-axes against the substrate varied. The difference in regulation accuracy between the $a$ - and $c$-axes may be important key to clarifying the stereochemical conformations between carboxyl groups of the PDA film surface and calcite crystals. Rarefied structural analysis methods, for instance, polarized external reflection IR spectroscopy, may be effective to estimate the conformations of carboxyl groups on the PDA film surface.

\section{Conclusion}

It has appeared to be true that choices of polymorph and orientation controls are under genetic control in the biological systems. The present work is an attempt to clarify the mechan- 

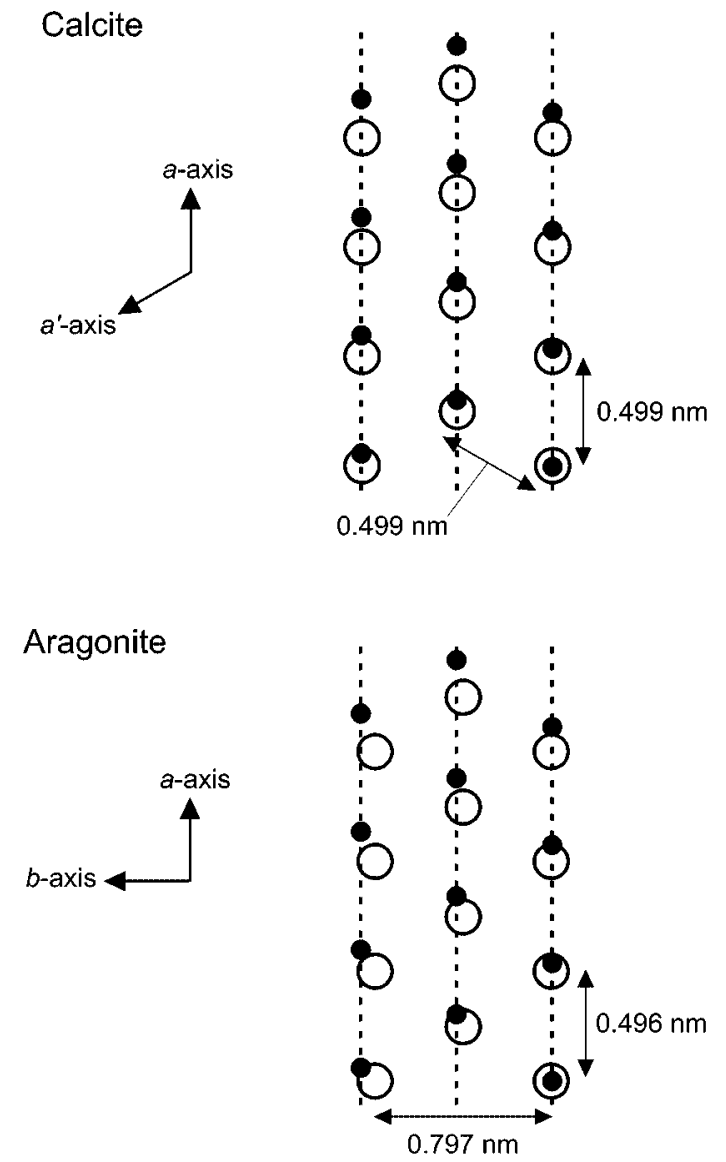

Fig. 7. Superimposition of calcite and aragonite (001) crystal faces (open circles) on the polymerized PDA molecular alignment (filled circles). Dashed lines indicate PDA polymerization direction.

ism of the calcium carbonate polymorphs selection and the directional control. $\mathrm{Mg}^{2+}$ ions are known to favor aragonite formation by inhibiting calcite growth. However, only calcite was nucleated on the polymerized PDA film irrespective of the presence of $\mathrm{Mg}^{2+}$ ions in the surrounding aqueous solutions. Obtained calcite crystals were aligned on the polymerized PDA film, and their $a$-axes were along the polymerization direction precisely, whereas the inclination of the $c$-axes against the substrate varied. Polymorphism and directional controls of calcium carbonate in the present experiments should be related to the calcite structure, but the similarity in the crystal structures of calcite and aragonite precludes the possibility of single achievement of geometric matching. A concerted mechanism of geometric matching and stereochemical effect, therefore, should determine the polymorphs and directions of calcium carbonate crystals simultaneously.

\section{References}

1) Mann, S., Archibald, D. D., Didymus, J. M., Douglas, T., Heywood, B. R., Meldrum, F. C. and Reeves, N. J., Science, Vol. 261, pp. 1286-1292 (1993).

2) Mann, S., Nature, Vol. 365, pp. 499-505 (1993).

3) Mann, S. (Ed.), "Biomimetic Materials Chemistry," $\mathrm{VCH}$
Publishers, New York (1996).

4) Dujardin, E. and Mann, S., Adv. Mater., Vol. 14, pp. 775-788 (2002).

5) Weiner, S. and Addadi, L., J. Mater. Chem., Vol. 7, pp. 689-702 (1997)

6) Mann, S., "Biomineralization: Chemical and Biochemical Perspectives," Ed. by Mann, S., Webb, J. and Williams, R. J. P., VCH Publishers, New York (1996) pp. 35-62.

7) Mann, S., Nature, Vol. 332, pp. 119-124 (1988).

8) Mann, S., "Biomineralization: Principles and Concepts in Bioinorganic Materials Chemistry," Oxford University Press, Oxford (2001).

9) Petty, M. C., "Langmuir-Blodgett Films: An Introduction," Cambridge University Press, Cambridge (1990).

10) Ulman, A., "An Introduction for Ultrathin Organic Films: from Langmuir-Blodgett to Self-Assembly," Academic Press, San Diego (1991).

11) Vos, J. G., Forster, R. J. and Keyes, T. E., "Interfacial Supramolecular Assemblies,” John Wiley \& Sons, West Sussex (2003).

12) Sato, K., Kumagai, Y. and Tanaka, J., J. Biomed. Mater. Res., Vol. 50, pp. 16-20 (2000).

13) Sato, K., Kogure, T., Kumagai, Y. and Tanaka, J., J. Colloid Interf. Sci., Vol. 240, pp. 133-138 (2001).

14) Sato, K., Kumagai, Y., Ikoma, T., Watari, K. and Tanaka, J., J. Ceram. Soc. Japan, Vol. 113, pp. 112-115 (2005).

15) Berman, A., Ahn, D. J., Lio, A., Salmeron, M., Reichert, A. and Charych, D., Science, Vol. 269, pp. 515-518 (1995).

16) Berman, A. and Charych, D., J. Cryst. Growth, Vols. 198/199, pp. 796-801 (1999).

17) Berman, A. and Charych, D., Adv. Mater., Vol. 11, pp. 296-300 (1999).

18) Dingley, D. J. and Randle, V., J. Mater. Sci., Vol. 27, pp. 4545-4566 (1992).

19) Belcher, A. M., Wu, X. H., Christensen, R. J., Hansma, P. K., Stucky, G. D. and Morse, D. E., Nature, Vol. 381, pp. 56-58 (1996).

20) Falini, G., Albeck, S., Weiner, S. and Addadi, L., Science, Vol. 271, pp. 67-69 (1996).

21) Gower, L. A. and Tirrell, D. A., J. Cryst. Growth, Vol. 191, pp. 153-160 (1998).

22) Zhang, Y. and Dawe, R. A., Chem. Geol., Vol. 163, pp. 129-138 (2000).

23) Lio, A., Reichert, A., Nagy, J. O., Salmeron, M. and Charych, D. H., J. Vac. Sci. Technol. B, Vol. 14, pp. 1481-1485 (1996).

24) Kitano, Y., Bull. Chem. Soc. Jpn., Vol. 32, pp. 1980-1985 (1962).

25) Putman, C. A. J., Hansma, H. G., Gaub, H. E. and Hansma, P. K., Langmuir, Vol. 8, pp. 3014-3019 (1992).

26) Higashino, H., Mizoguchi, E. and Ogawa, K., Jpn. J. Appl. Phys., Vol. 36, pp. 319-325 (1997).

27) Goettgens, B. M., Tillmann, R. W., Radmacher, M. and Gaub, H. E., Langmuir, Vol. 8, pp. 1768-1774 (1992).

28) Lieser, G., Tieke, B. and Wegner, G., Thin Solid Films, Vol. 68, pp. 77-90 (1980).

29) Falini, G., Gazzano, M. and Ripamonti, A., J. Cryst. Growth, Vol. 137, pp. 577-584 (1994).

30) Kitamura, M., J. Colloid Interf. Sci., Vol. 236, pp. 318-327 (2001).

31) Bernar, R. A., Geochim. Cosmochim. Acta, Vol. 39, pp. 489-504 (1975).

32) Mackenzie, F. T., Bischoff, W. D., Bishop, F. C., Loijens, M., Schoonmaker, J. and Wollast, R., "Carbonates: Mineralogy and Chemistry," Ed. by Reeder, R. J., Mineralog. Soc. Am., Washington, DC (1983) pp. 97-144. 